Article

\title{
Modeling and Quantifying User Acceptance of Personalized Business Modes Based on TAM, Trust and Attitude
}

\author{
Jie Zhao ${ }^{1}$, Suping Fang ${ }^{1}$ and Peiquan Jin ${ }^{2, *}$ \\ 1 School of Business, Anhui University, Hefei 230601, China; 97040@ahu.edu.cn (J.Z.); \\ m16201039@stu.ahu.edu.cn (S.F.) \\ 2 School of Computer Science and Technology, University of Science and Technology of China, \\ Hefei 230027, China \\ * Correspondence: jpq@ustc.edu.cn
}

Received: 31 December 2017; Accepted: 29 January 2018; Published: 30 January 2018

\begin{abstract}
With the rapid development of economics and social businesses, users' business demand has changed a lot. More and more people want to personalize their business modes so that they can get better experiences in business and learning activities. The key factor of personalized business mode is to consider users' individual needs on business activities, so that users can receive differentiated services. Users' satisfaction on personalized services will effectively improve the consuming experience of users, which is helpful for business organizations to strengthen their competitive power in business environments. However, will users wish to participate in personalized businesses? This is a crucial issue for developing personalized businesses. Aiming to solve this problem, this paper analyzes the major factors influencing user acceptance of personalized business modes. Then, we propose a research model that enhances the TAM (Technology Acceptance Model) model with trust and attitude to depict the influence from several variables to user acceptance of personalized business modes. Further, we use the structural equation method to conduct an empirical analysis on questionnaire data from the Internet. The results in terms of many kinds of data analysis show that trust and the TAM factors (perceived usefulness and perceived ease of use) have significant influence on user acceptance of personalized business modes. In addition, there are partial intermediate relationships existing among the factors of the research model.
\end{abstract}

Keywords: personalized business mode; technology acceptance model; user acceptance; data analysis

\section{Introduction}

The program of "Made in China 2025", developed based on Germany's "Industrial 4.0", provides new opportunities for transforming and upgrading the manufacturing industry in China. It also becomes the material foundation for customized services. China's realization of the "Internet+" strategy aims to personalize businesses as "Internet+" and to make the coordinated development of manufacturing sectors as an important platform, including manufacturing clothing, home appliances, furniture, and other industries. Consequently, the development of customized services has been a dominant trend in today's business world. In addition, by December 2016, the number of Internet users in China has reached 731 million, and the majority of Internet users in China are 10-39 years old [1]. These people are familiar with and dependent on the Internet world, and gradually become the main consumers in the whole society. Thus, it is important to provide customized or personalized services for them. Customization is also called personalized service, through which enterprises provide customized services according to the needs of different users [2,3]. Nowadays, personalized service has been a key indicator in the development of enterprises, because it enables companies to 
offer consumers unique products and services by considering users' personal properties such as user profiles, personal preferences, style characteristics, and shopping behavior. The basis for developing personalized businesses is to understand:

(1) Are consumers willing to participate in personalized businesses?

(2) Which factors will impact the participation of users in customized services?

Making these issues clear is helpful for enterprises to improve users' participation of customization.

This paper aims to study the willingness of users in participating in personalized business modes. At present, academia has not formed a unified conclusion about this issue. The research of personalized business modes is still at the beginning stage and has not formed an authoritative theoretical system. Particularly, previous studies in personalized business modes mainly focused on customization technologies and web-based customization systems, and few were towards personalized business modes. Specifically, the intention of users to participate in personalized businesses has not yet been studied systematically.

In this paper, we first study the user acceptance of personalized business modes. In particular, we analyze the major factors that influence user acceptance of personalized business modes. Then, we augment the Technology Acceptance Model (TAM) [4] to construct a theoretical research model to describe the influence from several variables to user acceptance of personalized business modes. The research model integrates TAM with trust, and uses attitude as the mediating factor. After that, we use the structural-equation method to conduct an empirical analysis on questionnaire data from the Internet.

In summary, we make the following contributions in this paper:

(1) We integrate the Technology Acceptance Model (TAM) with trust and attitude to analyze the users' willingness to participate in personalized business modes, and provide some research ideas for the relevant research in the field of personalized business modes. To the best of our knowledge, this is the first study of integrating the TAM model with trust and attitude to analyze user acceptance of personalized business modes.

(2) We conduct questionnaire on the Internet, and perform systematical data analysis over the questionnaire data in terms of various metrics including reliability and validity.

(3) We present empirical data analysis using commercial software and obtain several results. The data analysis consists of many aspects, including factor analysis, correlation analysis, regression analysis, mediating effect analysis, control variable analysis, and hypothesis evaluation. The results show that trust and the TAM factors (perceived usefulness and perceived ease of use) have significant influence on user acceptance of personalized business modes. In addition, there are partial intermediate relationships existing among the factors of the research model.

The study in this paper is helpful for enterprises to realize the importance of developing personalized business modes. It also reveals the major factors that influence personalized business modes, and quantifies the impacts of these factors on user acceptance of personalized business modes. Thus, this study can provide some management ideas for enterprises to develop personalized businesses. In addition, the study in this paper can further advance the relevant theories of personalized customization.

The remainder of this paper is structured as follows. Section 2 describes the related work and the differences between previous studies and this paper. Section 3 presents the research model as well as the hypothesis proposition. Section 4 describes the details of data collection. In Section 5, we discuss the results of data analysis. In Section 6, we conclude the entire paper. 


\section{Related Work}

\subsection{Personalized Business Modes}

Traditional business modes are typically based on product competition. Enterprises are concerned about the improvement of their own operational efficiency. However, as competition becomes increasingly fierce, enterprises may gradually lose their product-centric competitive advantages in the market. Thus, it is necessary for companies to adapt to the timely transformation from product-centric business modes to customer-centric business modes [5]. On the one hand, personalized customization is helpful to meet the personal needs of customers and to stimulate customer consumption and attract potential consumers. On the other hand, it also benefits the enterprise, and promotes the business development of the enterprise [6]. Choi and Lee [2] found that consumers generally preferred personalized products over standardized ones. This study argued that the consumer preference for personalized products depended on purchasing context and reversibility of choice.

With the development of economy and culture, it is difficult for the mass products to meet the diversified demands of consumers. Some traditional production models gradually lose their competitive advantages in the market, and enterprises need to further segment the market and operate professionally. For consumers, they pursue customized products or services with high quality, low cost and personalized features [3]. Consumers can choose their own style according to their preferences, such as color, size, and location. Businesses do not need to design mass products [7]. In addition, competition among enterprises is becoming more and more rigorous. How to personalize and form diversified and personalized requirements has been the focus of increasing competitive power for enterprises [8]. With the development of personalized business modes as well as the changes in various fields of society, many companies started to reduce costs and improve efficiency by optimizing personalized businesses [9]. Fogliatto et al. [10] reviewed the literature on mass customization over the last decade and provided a conceptual framework to support future research. They reviewed the concept, economics, success factors, and enablers of mass customization. To overcome the gap between customization and personalization, Wang and Ma [11] presented a framework for personalized production based on the concepts of Industry 4.0.

Previous research on personalized business modes focused on customization technologies. The research on product customization technology can be divided into three groups $[12,13]$. The first group is a management model based on customer demands, the second one is a management model based on product configuration, and the third one is a management mode based on customer online customization. Customization technologies were mainly used to build human-computer interaction platforms. On such platforms, users can select their own product components and participate in product research and development. In addition, web-based technologies offer to enterprises great support to provide personalized online services for their customers. As one of the hottest web-based technologies, recommender systems aim to automatically generate personalized suggestions of products/services to customers (businesses or individuals). Wu et al. [14] pointed out that, although recommender systems have been well studied, there are still two challenges in the development of a recommender system, particularly in real-world B2B e-services. Accordingly, they proposed a method for modeling fuzzy tree-structured user preferences. A recommendation approach to recommending tree-structured items was then developed. This study also applied the proposed recommendation approach to the development of a web-based business partner recommender system. Kim et al. [15] claimed that a Business Activity Monitoring (BAM) system should provide personalized monitoring capabilities. Therefore, they developed a personalized BAM system. Many clothing enterprises adapt custom online customization management mode to develop personalized business. Customers chose the elements of garment design to obtain customized products, such as the United States Mysuit system, VANCL system and other systems. Researchers at Nanyang Technology University set up a product customization platform based on network, the platform will be between all departments of the enterprise network services focused on network platform, proposed a GPF (generic product family) 
model, using XML document as the middleware for communication should be between the application and the GPF model [16]. Yang et al. added a custom system function module in the enterprise CIM system, established a kind of information resources can be shared e-commerce sales mode [17]. Recently, several mass customizers connected their sales configurators with social-network based software. This is not surprising because social-network software enables an interactive and socially rich shopping experience, which makes shopping with a mass-customization toolkit more similar to retail shopping. However, research on the use of social-network software by mass customizers are very limited, i.e., almost all previous studies on mass-customization toolkits were focused on the dynamic interaction between sales configurators and potential customers. Based on a survey on 277 real online sales configurators, Grosso et al. [18] identified eight ways in which online sales configurators can connect with social-network software. Nowadays, with the rapid development of information technologies (e.g., web 2.0, cloud computing, and virtual reality) and manufacturing technologies (e.g., additive manufacturing), users become more actively involved in product development processes to create personalized products with higher efficiency. This emerging manufacturing paradigm is known as mass personalization, of which user experiences (e.g., emotional factors and product utility), co-creation (e.g., user participation), and product change (e.g., modular design) are regarded as three key characteristics [19].

On the other hand, research on personalized business modes has focused on enterprise applications. With the development of electronic commerce, enterprises tried to develop enterprise customization system to gain or maintain competitive advantage. The product category involves clothing, electronic products and so on. On the premise of functional analysis, the enterprise divided and designed a series of functional modules, which could form different products through the selection or combination of modules, which satisfied the different demand of market [20]. The enterprise system of personalized customization has emerged, and has achieved remarkable economic and social benefits. In western countries, enterprise Internet system construction has basically completed the transformation from the first stage to the second stage, and began to gradually transition to the third stage. In some countries outside China, to maintain the existing market position or for a new position, leaders of many high technology industries were actively developing customized businesses. This trend is especially common in the manufacturing industries in the U.S., Germany, and Japan. The customized web system established by DELL provided personalized services to users all over the world based on understanding the real needs of users. In the customized business carried out by the Internet companies in the United States, consumers designed products and reduced costs. Panasonic has carried out modular production. Users can customize standardized components and accessories to get personalized products. Buick's North American website set up customized service customization, users could not only choose the engine type, tire style, body color and other parameters could also indicate the name of the owner in writing the quasi car back, the system would eventually be calculated according to the parameters chosen by the customer, after a month, consumers could buy the car of "the one and only". In China, the construction of enterprise web system was still in the primary stage of development. The main function of enterprise web system was product introduction and enterprise propaganda. Haier has opened a personalized custom system to provide customized business to consumers, consumers could choose their own capacity, style and other customized products according to their individual needs, and customized the products they need. Personalized customization has gradually developed into a more popular business mode, and domestic personality customization has been stimulated by the existing foreign successful cases, and it also shows a trend of vigorous development. In early 2005, some enterprises have begun to explore personalized custom T-shirts, quilts and other gifts in China, such as www.tshe.com and www.productdiy.cn. Lv et al. [21] investigated a two-dimensional model involving both vertically differentiated product preferences and horizontally differentiated personalization services.

The research of personalized business modes has not formed an authoritative theoretical system, but it is still in the initial stage of active exploration. The researches on personalized business modes 
are mainly focused on customization technologies and web-based customization systems. On the other hand, the study of personalized business modes focus on enterprise application level for customization, and personalized business modes have been gradually become a popular business mode. However, the intention of users to participate in personalized businesses has not yet been studied explicitly.

\subsection{Technology Adoption Models}

After the industrial revolution in the 1900s, due to the development of modern economics and the intensification of competition, many researchers began to study consumer behavior and proposed several technology adoption models [22,23]. Mehrabian and Russell put forward the SOR model (Stimulus-Organism-Response) based on the theory of cognitive psychology. They claimed that stimulus (S) with the organism of brain $(\mathrm{O})$ can lead to people's reactions $(\mathrm{R})$ [24]. The theory of reasoned action (TRA) model was first proposed for social psychology [25]. According to the TRA theory, a person can make a rational and comprehensive consideration of his own factors as well as the significance and consequences of his actions based on the value judgments made by individuals in social life. Further, the TRA model was used in business areas, e.g., for predicting user acceptance of e-shopping on the web [26]. In 1989, Davis et al. proposed the TAM model (Technology Acceptance Model) [4], which was first used to explain and predict user acceptance of computer technologies. The TAM model considers whether people accept an information system or not. Basically, if an information system can help people do their jobs better, it is perceived as useful. On the other hand, if an information system is easy to use, it is perceived to be easy to use. Most of the behavioral factors in the TAM model focus on describing user behavior to accept or reject the use of new technologies. Accordingly, the TAM model defines two variables, namely perceived usefulness and perceived ease of use, to quantify user attitude to information technology, which in turn can be used to measure user acceptance of information technologies.

Although the TAM model is initially designed to explain and predict behavior of individuals on the use of information systems, it has been used in many studies, especially in E-commerce related studies. That is mainly because E-commerce is a technology-driven area that is based on new information technologies such as web, mobile computing, and recommendation. Ha et al. [27] as well as $\mathrm{Lu}$ and $\mathrm{Su}$ [28] used the TAM model to predict the acceptance and use of consumer online shopping. Gefen et al. [29] studied the MBA and senior students' willingness of buying books from Amazon. Vijayasarathy et al. also used this model to study the acceptance of online shopping by investigating 281 young people in the U.S. [30]. There are other works concentrated on the online shopping behavior of network consumers. For example, Ko et al. used the TAM model to study consumer adoption of mobile shopping for fashion products in Korea [31]. Xie and Lee [32] pointed out that in the TAM model, perceived usefulness and perceived ease of use affect users' attitude to and willingness to accept information technologies, and technologies that are easy to understand and use will be more attractive to people. Many scholars have used the TAM model to predict the acceptance and use of consumer online shopping [33-35]. Some researchers pointed out that trust has an impact on consumer acceptance intention [36,37].

Previous studies have demonstrated the applicability of the TAM model to electronic businesses, especially to online shopping. In this paper, we focus on the personalized business in the network environment. The users in this study are mainly supposed to be users in electronic business. Thus, it is a reasonable choice to consider the TAM model to model and quantify user acceptance of personal business modes. On the other hand, differing from the traditional TAM model, we integrate trust with TAM and propose to use attitude as the mediate factor, forming an augmented TAM model that is more suitable for the research issue of this paper. 


\section{Research Methodologies and Hypotheses}

\subsection{Research Model}

The Technology Acceptance Model (TAM) has been widely used for predicting and explaining user behavior and IT usage [4]. According to the TAM model, individual behavior of an information system is determined using the system and the use of behavior intentions. Behavior intentions are affected by perceived usefulness and attitude. Here, attitude refers to the individual evaluation on the information system, i.e., positive or negative reactions. The use of an information system is mainly impacted by two factors, namely perceived usefulness and perceived ease of use. The perceived usefulness refers to the effect of the perceived use of the information system on improving the performance of the system. The perceived ease of use refers to the individual perceived ease of the use of the information system. When the individual perception information system is easier to use, the perceived ease of use will have a positive impact. The perceived usefulness and perceived ease of use are both affected by external factors. In addition, the perceived ease of use also positively affects the perceived usefulness.

In this paper, we first select the main factors in the TAM model as basic independent variables, i.e., perceived usefulness (Perceived Usefulness, PU) and perceived ease of use (Perceived Ease of Use, PEOU). Further, we introduce trust as a new independent variable. Trust has been recognized as a critical factor in online environment [29,36]; thus, it is reasonable to introduce it into the research model. The behavior intention (behavior Intention, BI) is designed to be the dependent variable. In the study of behavior intention, attitude has been commonly recognized as a variable that affects the willingness of behavior. Thus, we choose attitude as the mediating variable. On this basis, this paper puts forward the research model of consumers' willingness to participate in enterprise customization. Figure 1 summarizes the research model of this paper.

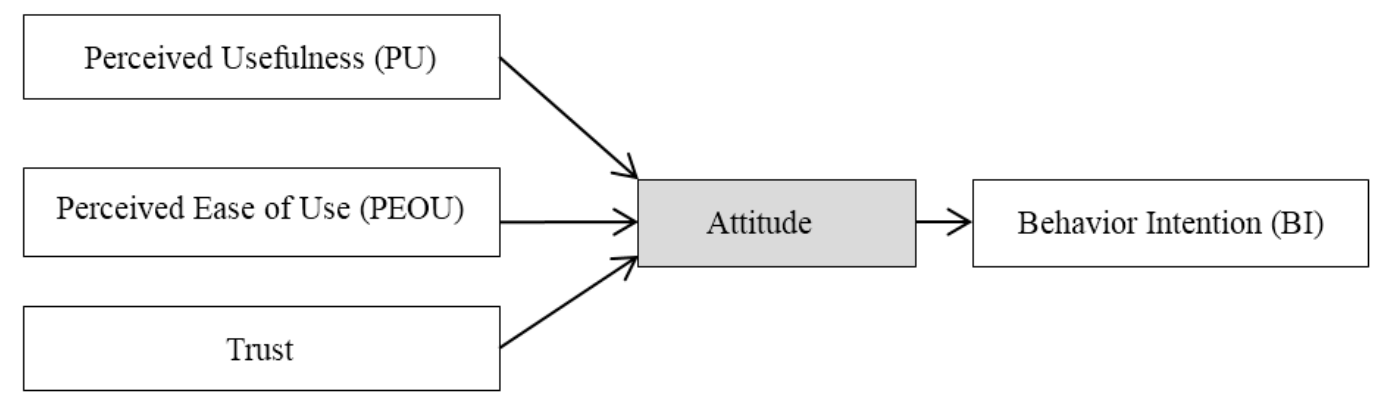

Figure 1. The research model.

\subsection{Research Hypothesis}

Users have a big impact on the development of personalized businesses. That means personalized businesses have to be accepted by users. Thus, enterprises need to take account of some the factors influencing users' behavior in the development of customized businesses. It has been studied before that participating in customization activities can bring some benefits for participants [38,39]. At the same time, the development of customized businesses needs to consider the difficulty for users to participate in personalized businesses. Some companies may build network-based information systems to assist users for using personalized businesses. Such systems can make users feel that customized businesses are easy to use.

The TAM model uses perceived usefulness and perceived ease of use to reflect behavior intention. Perceived ease of use refers to the individual's perceived ease of using an information system, while perceived usefulness refers to the degree to which individuals perceive the use of information systems to improve their work performance [4]. Many previous studies have shown that perceived ease of use not only affects the willingness of participating but also affects the perceived usefulness [33]. 
In the environment of personalized businesses, it is necessary for products or services to be easy to understand and use, otherwise consumers will not accept new products or services.

According to the research model presented in Section 3.1, there are three independent variables, namely perceived usefulness, perceived ease of use, and trust. In addition, there is one mediating variable called attitude. These variables are supposed to impact the dependent variable named behavior intention. Thus, to reveal the relationships among these factors, we first raise the following research questions, as listed in Table 1 . The right column in Table 1 shows the corresponding hypotheses that are proposed to answer the research question. Q1 is to find out the influential relationship among the independent variables of the research model. Q2 is to find out the influential relationship between independent variables and the mediating variable. Q3 is to find out the influential relationship between the mediating variable and the dependent variable. Finally, Q4 aims to find out the intermediate relationship among all the factors in the research model.

Table 1. Research questions and corresponding hypotheses.

\begin{tabular}{ccc}
\hline Question Number & Research Question & Corresponding Hypothesis \\
\hline Q1 & $\begin{array}{c}\text { What relationship exists among the } \\
\text { independent variables of the research model? }\end{array}$ & $\mathrm{H} 1$ \\
\hline Q2 & $\begin{array}{c}\text { What influences exist between independent } \\
\text { variables and the mediating variable (attitude)? }\end{array}$ & $\mathrm{H} 2, \mathrm{H} 3, \mathrm{H} 9$ \\
\hline Q3 & $\begin{array}{c}\text { How does the mediating variable (attitude) } \\
\text { impact the dependent variable? }\end{array}$ & $\mathrm{H} 4$ \\
\hline Q4 & $\begin{array}{c}\text { How does a factor in the research model play } \\
\text { intermediate role between other factors? }\end{array}$ & $\mathrm{H} 5, \mathrm{H} 6, \mathrm{H} 7, \mathrm{H} 8, \mathrm{H} 10$ \\
\hline
\end{tabular}

The details about each hypothesis are presented as follows. The objective of each hypothesis can be found in Table 1.

Perceived ease of use refers to the individual's perceived ease of using an information system. If an information system is perceived to be much accessible, it is much likely that users have a positive attitude on using the information system. In personalized businesses, perceived ease of use means that consumers can easily participate in personalized businesses, and the interaction process with the enterprise is simple and easy to use. On the other hand, the complexity of business systems and processes will hinder users to participate in personalized businesses. Therefore, we make the following hypotheses (H1 and $\mathrm{H} 2)$.

Hypothesis 1 (H1). Users' perceived ease of use of personalized business modes positively affects their perceived usefulness of personalized business modes.

Hypothesis 2 (H2). Users' perceived ease of use of personalized business modes affects their attitude to personalized business modes.

Perceived usefulness refers to the degree to which individuals perceive the use of information systems to improve their work performance. If users think that information systems are useful, they are likely to have a positive attitude on using them. Attracting and motivating the public to participate in the process of personalized business is important to personalized businesses, because participating in personalized tailor-made activities can bring certain benefits to participants and satisfy their actual needs [38]. Some researchers summarized these factors as internal motivation and external motivation, while others divided them into personal motivation and social motivation [39]. As a result, personalized business needs to satisfy user needs, and users' perceived usefulness of personalized business modes will impact their attitude on using personalized businesses. Therefore, we make hypothesis $\mathrm{H} 3$, which is specified as follows. 
Hypothesis 3 (H3). Users' perceived usefulness of personalized business modes affects their attitude to personalized business modes.

Based on the traditional TAM model, many previous works have empirically evaluated the positive influence of attitude on the willingness to participate. Users' willingness to participate in the customization of the enterprise is influenced by their subjective attitude. More active attitude may lead to high possibility of participating in personalized businesses. Based on such assumption, we make hypothesis $\mathrm{H} 4$.

Hypothesis 4 (H4). Users' attitude to personalized business modes affects their behavior intention on personalized business modes.

Venkatesh et al. [40] proposed that there must be a corresponding attitude towards real behavior before an action occurs. In other words, attitude affects user acceptance behavior [40]. User acceptance attitude refers to the overall tendency of users to participate in personalized businesses, which is impacted by cognitive tendency, emotional expression, and behavioral tendency of using personalized products or services. Users have to go through the behavioral attitude phase before generating actual participation intention. This means that perceived ease of use and perceived usefulness will first inspire users' attitude towards the customization of the enterprise. Thus, we make the following hypotheses (H5 and $\mathrm{H} 6$ ) to reflect the above observations.

Hypothesis 5 (H5). Users' attitude to personalized business modes plays an intermediary role in perceived ease of use and behavior intention.

Hypothesis 6 (H6). Users' attitude to personalized business modes plays an intermediary role in perceived usefulness and behavior intention.

According to the TAM model, perceived usefulness plays an intermediary role among perceived ease of use, attitude, and willingness to participate. If the personalized business of an enterprise is relatively simple to use, we can imagine that users' attitude on using personalized business will be stimulated, resulting in a positive attitude on participating in personalized business. Therefore, we make the following hypotheses (H7 and H8).

Hypothesis 7 (H7). Users' perceived usefulness of personalized business modes plays an intermediary role in perceived ease of use and attitude.

Hypothesis 8 (H8). Users' perceived usefulness of personalized business modes plays an intermediary role in perceived ease of use and behavior intention.

In recent years, trust has been widely studied in electronic commerce and other areas. Koo [41] and Chang et al. [42] showed that trust was strongly associated with attitude to products and services as well as attitude to purchasing behaviors. Gefen et al. pointed out that trust was very important for network merchants, and trust was not only a key factor influencing users' acceptance of information technologies, but also a key factor attracting consumers [36]. Heijden et al. studied the trust variables of consumers in Holland. They found that trust had an impact on the use intention of electronic websites [37]. Chen and Yang [43] showed that trust not only had a positive impact on users' willingness to use microblogging services. They concluded that trust can be used as an important indicator of consumer behavior in the Internet environment. In the scope of personalized businesses, we note that there is a value exchange between users and enterprises. In the process of such a value exchange, the trust between the two sides is a critical factor. In personalized businesses, the credit of the enterprise is very important. Therefore, we attempt to conduct an empirical research on whether trust has 
a significant impact on attitude and behavior intention. Thus, we make the following hypothesis (H9 and H10).

Hypothesis 9 (H9). Users' trust on personalized business modes affects their attitude to personalized business modes.

Hypothesis 10 (H10). Users' attitude to personalized business modes plays an intermediary role in trust and behavior intention.

\section{Questionnaire and Data Collection}

\subsection{Questionnaire Design}

Table 1 shows the design of the questionnaire indicators of our study. Most questions can be found in previous studies to ensure the validity and reliability of the questionnaire. Each item of the questionnaire is assessed using a five-point Likert scale from the bottom value "strongly disagree" to the top value "strongly agree" (see Table 2). The observation index is set up according to the environment of personalized businesses.

Table 2. Indicators of the questionnaire.

\begin{tabular}{|c|c|c|}
\hline Construct & Question Code & Measurement Problem \\
\hline \multirow{4}{*}{ PU } & PU1 & $\begin{array}{l}\text { If I were to adopt personalized business modes, it would enable me to purchase } \\
\text { favorite products }\end{array}$ \\
\hline & PU2 & $\begin{array}{l}\text { If I were to adopt personalized business modes, it would enable me to broaden } \\
\text { my understanding of the product or service }\end{array}$ \\
\hline & PU3 & $\begin{array}{l}\text { If I were to adopt personalized business modes, the effect of purchasing goods or } \\
\text { services would improve }\end{array}$ \\
\hline & PU4 & $\begin{array}{l}\text { If I were to adopt personalized business modes, it would satisfy my personal } \\
\text { consumption needs }\end{array}$ \\
\hline \multirow{3}{*}{ PEOU } & PEOU1 & Learning how to participate in personalized business would be easy for me \\
\hline & PEOU2 & Participation in enterprise personalized business takes less time and effort \\
\hline & PEOU3 & $\begin{array}{l}\text { In the process of enterprise personalized business, enterprises provide clear and } \\
\text { easy communication }\end{array}$ \\
\hline \multirow{5}{*}{ Trust } & TR1 & $\begin{array}{l}\text { I'll think products or services purchased by personalized business modes will } \\
\text { be trustworthy }\end{array}$ \\
\hline & TR2 & $\begin{array}{l}\text { I believe that companies will take into account customer needs in the process } \\
\text { of customization }\end{array}$ \\
\hline & TR3 & I believe the expected effect of customized products or services is predictable \\
\hline & TR4 & I believe that the after-sale service of personalized business modes is guaranteed \\
\hline & TR5 & $\begin{array}{l}\text { I believe the organizers will provide meticulous service to help me solve all kinds } \\
\text { of problems in the process of customization }\end{array}$ \\
\hline \multirow{4}{*}{ Attitude } & AT1 & I think it's a good idea to take part in customization \\
\hline & AT2 & I like to experience personalized business modes \\
\hline & AT3 & Participating in personalized business modes will bring me a pleasant experience \\
\hline & AT4 & I'll be positive about personalized business modes \\
\hline \multirow{4}{*}{ BI } & BI1 & I'll intend to experience personalized business as soon as possible. \\
\hline & BI2 & I intend to continue to participate in the personalized business of the enterprise \\
\hline & $\mathrm{BI} 3$ & I will recommend personalized business modes to my friends \\
\hline & BI4 & I have an urge to participate in personalized business \\
\hline
\end{tabular}


The questionnaire consists of two parts: (1) demographic questionnaire; and (2) questionnaire on independent variable, mediating variable, and dependent variable. The explanations of these parts are as follows:

1. Demographic questionnaire: This part mainly surveys the gender, age, educational background, income, etc.

2. Questionnaire on independent variables, mediating variables and dependent variables: This part of questionnaire is the core of the whole questionnaire. This study contains five latent variables: perceived usefulness, perceived ease of use, trust, attitude, and behavior intention. After a preliminary investigation, we make the formal index of investigation, as shown in Table 2.

\subsection{Data Collection}

We conduct an online survey to verify our research model. In the survey, total 210 questionnaires were issued, and 208 questionnaires were received within one week. Seventeen questionnaires that contained inconsistent answers or incomplete information filling were removed from the dataset. Consequently, 191 valid questionnaires were collected.

In the collected dataset, the proportions of males and females are $40.3 \%$ and $59.7 \%$, respectively. The age of surveyed users ranges from 18 to 40 years old, and most of the users, i.e., $80.6 \%$, are between 18 and 25 years old. Ninety percent of users have undergraduate or graduate degrees.

\subsection{Reliability and Validity}

We first use the SPSS tool to validate the reliability and validity of the collected data. The internal-consistency reliability reflects the stability of individual measurement items across replications from the same information source. This kind of reliability is assessed by computing Cronbach's $\alpha$, whose coefficients for the eight constructs are over 0.6 , indicating a reasonable level of internal consistency among the items [42]. The validity test is to examine the authenticity of the subjects. The analysis results of the reliability and validity of the collected data are shown in Table 3. It shows that the Cronbach's $\alpha$ of all variables are over 0.8 , and the overall Cronbach's $\alpha$ is 0.935 , indicating that the scale system is highly reliable. All the values of KMO of the variables are greater than 0.7 , except the value of KMO of PU. The significant level of Bartlett's test is less than 0.05 , which shows that the factor analysis method is applicable to the questionnaire.

Table 3. Reliability and validity analysis on variables.

\begin{tabular}{cccccc}
\hline \multirow{2}{*}{ Variable } & \multirow{2}{*}{ Cronbach's $\alpha$} & \multirow{2}{*}{ KMO Value } & \multicolumn{3}{c}{ Bartlett's Test } \\
\cline { 4 - 6 } & & & Approximate Chi-Square & Freedom & Significance \\
\hline PU & 0.841 & 0.800 & 313.315 & 6 & $<0.001$ \\
PEOU & 0.833 & 0.687 & 235.547 & 3 & $<0.001$ \\
Trust & 0.875 & 0.848 & 462.343 & 10 & $<0.001$ \\
Attitude & 0.885 & 0.825 & 414.888 & 6 & $<0.001$ \\
BI & 0.859 & 0.810 & 340.999 & 6 & $<0.001$ \\
\hline \multicolumn{7}{r}{ Cronbach's $\alpha=0.935}$.
\end{tabular}

\section{Data Analysis}

In this section, we perform data analysis on the collected data to evaluate the hypotheses. In Section 5.1, we use the principal component analysis and maximum likelihood method to carry out factor analysis to ensure the design rationality of model variables. In Section 5.2, we perform correlation analysis to find out the correlations among the independent variables, the mediator variable, and the dependent variable. Correlation analysis refers to the analysis on two or more correlated variable elements to measure the closeness of the variable factors. In Section 5.3, we conduct regression analysis to find out the causal relationship between factors of the research model, including PU, PEOU, 
trust, attitude, and BI. In Section 5.4, we measure the mediating effects of attitude and PU in the research model. In Section 5.5, we test the interferential effects of the control variables based on different types of sample data.

\subsection{Factor Analysis}

Factor analysis aims to find out the number of factors that affect the observed variables, as well as the correlations between each factor and each of the observed variables in an attempt to reveal the inherent structure of a relatively large set of variables. In this subsection, we will use the SPSS software to perform factor analysis on the collected dataset. Particularly, we use the maximum likelihood method and the principal component analysis method to analyze the exploratory factors.

\subsubsection{Independent Variables}

Exploratory factor analysis on independent variables is shown in Table 4. The cumulative contribution rate of the three factors is $70 \%$, indicating that the content of the questionnaire can be well explained by the three factors. The orthogonal rotation is performed by using the maximum variance rotation method. The results are shown in Table 5.

Table 4. Variance of independent variables.

\begin{tabular}{ccccccc}
\hline \multirow{2}{*}{ Component } & \multicolumn{3}{c}{ Initial Eigenvalue } & \multicolumn{2}{c}{ Sum of Squares of Extracted Load } \\
\cline { 2 - 7 } & Total & $\begin{array}{c}\text { Percentage } \\
\text { Variance }\end{array}$ & $\begin{array}{c}\text { Cumulative } \\
\text { Percentage }\end{array}$ & Total & $\begin{array}{c}\text { Percentage } \\
\text { Variance }\end{array}$ & $\begin{array}{c}\text { Cumulative } \\
\text { Percentage }\end{array}$ \\
\hline 1 & 5.518 & 45.984 & 45.984 & 5.518 & 45.984 & 45.984 \\
2 & 1.524 & 12.700 & 58.684 & 1.524 & 12.700 & 58.684 \\
3 & 1.357 & 11.311 & 69.995 & 1.357 & 11.311 & 69.995 \\
4 & 0.615 & 5.128 & 75.123 & & & \\
5 & 0.580 & 4.833 & 79.955 & & & \\
6 & 0.491 & 4.090 & 84.046 & & & \\
7 & 0.453 & 3.776 & 87.822 & & & \\
8 & 0.358 & 2.987 & 90.809 & & & \\
9 & 0.347 & 2.895 & 93.704 & & & \\
10 & 0.295 & 2.460 & 96.163 & & & \\
11 & 0.267 & 2.229 & 98.392 & & & \\
12 & 0.193 & 1.608 & 100.000 & & & \\
\hline
\end{tabular}

Table 5. Factor loading matrix.

\begin{tabular}{|c|c|c|c|}
\hline \multirow{2}{*}{ Questions } & \multicolumn{3}{|c|}{ Component } \\
\hline & PU & PEOU & Trust \\
\hline $\begin{array}{l}\text { Q101: If I were to adopt personalized business modes, it would } \\
\text { enable me to purchase favorite products }\end{array}$ & 0.816 & & \\
\hline $\begin{array}{l}\text { Q102: If I were to adopt personalized business modes, it would } \\
\text { enable me to broaden my understanding of the product or service }\end{array}$ & 0.827 & & \\
\hline $\begin{array}{l}\text { Q103: If I were to adopt personalized business modes, the effect of } \\
\text { purchasing goods or services would improve }\end{array}$ & 0.691 & & \\
\hline $\begin{array}{l}\text { Q104: If I were to adopt personalized business modes, it would } \\
\text { satisfy my personal consumption needs }\end{array}$ & 0.791 & & \\
\hline $\begin{array}{l}\text { Q201: Learning how to participate in personalized business would be } \\
\text { easy for me. }\end{array}$ & & 0.854 & \\
\hline $\begin{array}{l}\text { Q202: Participation in enterprise personalized business takes less } \\
\text { time and effort }\end{array}$ & & 0.904 & \\
\hline
\end{tabular}


Table 5. Cont.

\begin{tabular}{|c|c|c|c|}
\hline \multirow{2}{*}{ Questions } & \multicolumn{3}{|c|}{ Component } \\
\hline & PU & PEOU & Trust \\
\hline $\begin{array}{l}\text { Q203: In the process of enterprise personalized business, enterprises } \\
\text { provide clear and easy communication }\end{array}$ & & 0.697 & \\
\hline $\begin{array}{l}\text { Q301: I'll think products or services purchased by personalized } \\
\text { business modes will be trustworthy }\end{array}$ & & & 0.773 \\
\hline $\begin{array}{l}\text { Q302: I believe that companies will take into account customer needs } \\
\text { in the process of customization }\end{array}$ & & & 0.750 \\
\hline $\begin{array}{l}\text { Q303: I believe the expected effect of customized products or services } \\
\text { is predictable }\end{array}$ & & & 0.774 \\
\hline $\begin{array}{l}\text { Q304: I believe that the after-sale service of personalized business } \\
\text { modes is guaranteed }\end{array}$ & & & 0.810 \\
\hline $\begin{array}{l}\text { Q305: I believe the organizers will provide meticulous service to help } \\
\text { me solve all kinds of problems in the process of customization }\end{array}$ & & & 0.730 \\
\hline
\end{tabular}

\subsubsection{Mediating Variable}

The mediating variable is explored by factorial analysis to explain the total variance of the variable. The results are shown in Table 6. The cumulative contribution rate of one factor is $74.397 \%$, which can well explain the contents of the original questionnaire.

Table 6. Variance of the mediating variable.

\begin{tabular}{ccccccc}
\hline \multirow{2}{*}{ Component } & \multicolumn{3}{c}{ Initial Eigenvalue } & \multicolumn{2}{c}{ Sum of Squares of Extracted Load } \\
\cline { 2 - 6 } & Total & $\begin{array}{c}\text { Percentage } \\
\text { Variance }\end{array}$ & $\begin{array}{c}\text { Cumulative } \\
\text { Percentage }\end{array}$ & Total & $\begin{array}{c}\text { Percentage } \\
\text { Variance }\end{array}$ & $\begin{array}{c}\text { Cumulative } \\
\text { Percentage }\end{array}$ \\
\hline 1 & 2.976 & 74.397 & 74.397 & 2.976 & 74.397 & 74.397 \\
2 & 0.431 & 10.780 & 85.177 & & & \\
3 & 0.344 & 8.610 & 93.787 & & \\
4 & 0.249 & 6.213 & 100.000 & & & \\
\hline
\end{tabular}

From the load matrix of the mediating variable, as shown in Table 7, we can see that the factor scores are greater than 0.8 . This means that these factors can be classified into one class, which is exactly the attitude.

Table 7. Load matrix of the attitude factor.

\begin{tabular}{lc}
\hline \multicolumn{1}{c}{ Questions } & Component \\
\cline { 2 - 2 } & Attitude \\
\hline Q401: I think it's a good idea to take part in customization & 0.832 \\
Q402: I like to experience personalized business modes & 0.864 \\
Q403: Participating in personalized business modes will & 0.893 \\
bring me a pleasant experience & 0.860 \\
Q404: I'll be positive about personalized business modes & \\
\hline
\end{tabular}

\subsubsection{Dependent Variable}

The main variance of the dependent variables is explained by the factor analysis on the dependent variables. As shown in Table 8, the cumulative contribution rate of one factor is $70.475 \%$, which can well explain the contents of the original questionnaire. 
Table 8. Variance of the behavior intention variable.

\begin{tabular}{ccccccc}
\hline \multirow{2}{*}{ Component } & \multicolumn{3}{c}{ Initial Eigenvalue } & \multicolumn{2}{c}{ Sum of Squares of Extracted Load } \\
\cline { 2 - 6 } & Total & $\begin{array}{c}\text { Percentage } \\
\text { Variance }\end{array}$ & $\begin{array}{c}\text { Cumulative } \\
\text { Percentage }\end{array}$ & Total & $\begin{array}{c}\text { Percentage } \\
\text { Variance }\end{array}$ & $\begin{array}{c}\text { Cumulative } \\
\text { Percentage }\end{array}$ \\
\hline 1 & 2.819 & 70.475 & 70.475 & 2.819 & 70.475 & 70.475 \\
2 & 0.503 & 12.570 & 83.045 & & & \\
3 & 0.351 & 8.782 & 91.827 & & & \\
4 & 0.327 & 8.173 & 100.000 & & & \\
\hline
\end{tabular}

The results of the variable factor load are shown in Table 9, which shows that the factor scores are greater than 0.8 . Thus, they can be classified into one class, and this class is named as behavior intention according to the characteristics of the question.

Table 9. Load matrix of the behavior intention factor.

\begin{tabular}{lc}
\hline \multicolumn{1}{c}{ Questions } & Component \\
\cline { 2 - 2 } & Behavior Intention \\
\hline Q501: I'll intend to experience personalized business as soon as possible & 0.857 \\
Q502: I intend to continue to participate in the personalized business of the enterprise & 0.832 \\
Q503: I will recommend personalized business modes to my friends & 0.850 \\
Q504: I have an urge to participate in personalized business & 0.819 \\
\hline
\end{tabular}

\subsection{Correlation Analysis}

Correlation analysis is a statistical method that aims to reveal whether there is a relationship between variables. If there is a relationship, we need to quantify the strength of this relationship. As correlation analysis generally employs the Pearson coefficient to express the linear relationship among variables, in this paper we also use the Pearson correlation analysis method to analyze the correlation between PU, PEOU, trust, attitude, and BI. In particular, we use $r$ to represent the Pearson correlation coefficient. A positive value of $r$ indicates that the two variables tested are positive correlated, while a negative value of $r$ means the two variables have a negative correlation. When $-1<r<1$, the greater the absolute value of $r$, the greater the correlation between the two variables. Table 10 shows the mean value of each variable according to the Pearson analysis.

Table 10. Overall results of the correlation analysis.

\begin{tabular}{cccccc}
\hline & PU & PEOU & Trust & Attitude & BI \\
\hline Overall Mean & 4.045 & 3.506 & 3.699 & 3.952 & 3.598 \\
Standard Deviation & 0.684 & 0.795 & 0.705 & 0.673 & 0.815 \\
\hline
\end{tabular}

As shown in Table 10, the mean value of behavior intention is 3.598, indicating high tendency of users' willingness to participate in personalized business. The mean value of perceived usefulness is 4 , indicating that perceived usefulness is more sensitive to the perception of the user. The mean value of perceived ease of use is 3.506, which is consistent with the relatively low sensitivity of users to technology in the age of information technology.

\subsubsection{Independent Variables and Attitude}

Table 11 shows the correlation analysis results between the three independent variables and the mediator variable (Attitude) is analyzed. 
Table 11. Correlation analysis (two-tailed) between independent variables and attitude.

\begin{tabular}{ccc}
\hline Independent Variable & Index & Mediation Variable (Attitude) \\
\hline \multirow{2}{*}{ PU } & Pearson correlation & 0.604 \\
& Significant (two-tailed) & $<0.001$ \\
\hline \multirow{2}{*}{ PEOU } & Pearson correlation & 0.407 \\
& Significant (two-tailed) & $<0.001$ \\
\hline \multirow{2}{*}{ Trust } & Pearson correlation & 0.682 \\
& Significant (two-tailed) & $<0.001$ \\
\hline
\end{tabular}

In Table 11, a value less than 0.001 means that the actual value is too small to be correctly shown in the SPSS software. For such values, SPSS always output 0.000 by default.

Table 11 shows that the correlation coefficients of perceived usefulness, perceived ease of use, and attitude towards trust are $0.604,0.407$ and 0.682 , respectively. The Pearson correlation coefficients of the three independent variables and the mediator variables are all positive. The significant is at the 0.001 level, meaning that the correlation between attitude and PU, PEOU, and trust is positive. The correlation between perceived ease of use and attitude is not tighter than that between the other two factors, indicating that in the digital age most users are not sensitive to the ease-of-use of personalized business. On the other hand, both perceived usefulness and trust have a high impact on attitude. Thus, Hypothesis 2, 3 and 9 are validated.

\subsubsection{Attitude and Behavior Intension}

The correlation analysis between attitude and behavior intention is shown in Table 12. The correlation coefficient of attitude towards behavior intention is 0.681 . The significance probability of attitude and behavior intention is less than 0.001 , which is significant at the 0.001 level. We can see from the table that attitude and behavior intention is positively correlated. The correlation coefficient of attitude towards behavior intention is higher than that between perceived usefulness and perceived ease of use. This shows that attitude has a high impact on behavior intention. As attitude and behavior intention are both subjective, we can see that users' attitude towards personalized business directly affects behavior intention. Thus, Hypothesis 4 is validated.

Table 12. Correlation analysis between attitude and behavior intention.

\begin{tabular}{ccc}
\hline Independent Variable & Index & Dependent Variable \\
\hline \multirow{2}{*}{ Attitude } & Pearson correlation & 0.681 \\
& Significant (two-tailed) & $<0.001$ \\
\hline
\end{tabular}

\subsubsection{Perceived Ease of Use and Perceived Usefulness}

The correlation analysis between perceived ease of use and perceived usefulness and is shown in Table 13. The correlation coefficient of perceived ease of use for perceived usefulness is 0.401 . The significance probability is less than 0.001 , which is significant at the 0.001 level. The correlation coefficient of perceived ease of use for perceived usefulness shows that users' usefulness assessment for personalized business is partly derived from the irritation of usability. The less the difficulty of personalized business is, the less time and effort users need to participate in personalized business. Consequently, we can see from the table that perceived ease of use and perceived usefulness are positively correlated. This indicates that Hypothesis 1 is validated. 
Table 13. Correlation analysis between perceived ease of use and perceived usefulness.

\begin{tabular}{ccc}
\hline Independent Variable & Index & Dependent Variable (PU) \\
\hline \multirow{2}{*}{ PEOU } & Pearson correlation & 0.401 \\
& Significant (two-tailed) & $<0.001$ \\
\hline
\end{tabular}

\subsection{Regression Analysis}

In this section, we use SPSS software to explain whether there is a causal relationship between the variables. We use the regression analysis as the basic tool for revealing causal relationships. Regression analysis can explore the magnitude of the influence between variables. It can also explore the direction of the impact between variables. If two or more variables have a causal relationship, the regression equation is expected to be established between them. In our study, we use the hierarchical regression method to detect the mediating effect between the argument and the dependent variable.

\subsubsection{Perceived Usefulness and Attitude}

We first perform regression analysis on perceived usefulness and attitudes. The results are shown in Table 14, which shows that the standardized regression coefficient of perceived usefulness is 0.604 . The $F$ value is 108.459 , showing that the $F$ test is passed. Table 4 shows that the regression effect is significant and the regression coefficient is positive. It indicates that users' perceived usefulness for personalized business has a significant positive impact on attitude when other factors remain unchanged, meaning that the original Hypothesis 3 is validated. The value of the Adjusted $R^{2}$ is 0.361 , which shows that the explanatory power of perceived usefulness to attitude is $36.1 \%$. This means that perceived usefulness has a significant positive effect on attitude of users to participate in personalized business. When perceived usefulness has a high value, users are much likely to have a positive attitude to participate in personalized businesses.

Table 14. Regression analysis on perceived usefulness and attitude.

\begin{tabular}{cccc}
\hline \multirow{2}{*}{ Variable } & \multicolumn{3}{c}{ Standardized Coefficient } \\
\cline { 2 - 4 } & $\beta$ & Significance \\
\hline PU & 0.604 & $<0.001$ \\
$F$ & & 108.459 & \\
$\mathrm{R}^{2}$ & & 0.365 & \\
Adjusted $\mathrm{R}^{2}$ & & 0.361 & \\
$N$ & & 191 & \\
\hline
\end{tabular}

\subsubsection{Perceived Ease of Use and Attitude}

In this section, we report the results of regression analysis on perceived ease of use and attitude. The results are shown in Table 15. We can conclude from the results that perceived ease of use has a positive effect on attitude. The standardized regression coefficient of perceived ease of use is 0.407 . The $F$ value is 37.546 , showing that the $F$ test is passed. Table 15 shows that the regression effect is significant and the regression coefficient is positive. It shows that users' perceived ease of use for personalized business has a significant positive impact on attitude. The value of the Adjusted $\mathrm{R}^{2}$ is 0.161 , which shows that perception is easy to use and its explanatory power to attitude is $16.1 \%$. In summary, Hypothesis 2 is validated.

Perceived ease of use positively affects the attitude of users participating in personalized businesses, because the less difficulty of personalized business will make users easier to use and participate in personalized businesses, yielding a positive attitude. 
Table 15. Regression analysis on perceived ease of use and attitude.

\begin{tabular}{cccc}
\hline \multirow{2}{*}{ Variable } & \multicolumn{3}{c}{ Standardized Coefficient } \\
\cline { 2 - 4 } & $\beta$ & \multicolumn{2}{c}{ Significance } \\
\hline PEOU & 0.407 & $<0.001$ \\
$F$ & & 37.546 & \\
$\mathrm{R}^{2}$ & & 0.166 & \\
Adjusted R & & 0.161 & \\
$N$ & & 191 & \\
\hline
\end{tabular}

\subsubsection{Trust and Attitude}

Next, we perform regression analysis on trust and attitude. The results are shown in Table 16. In Table 16, we can conclude that trust has a positive influence on attitude. The standardized regression coefficient of trust is 0.4682 . The $F$ value is 164.128 , showing that the $F$ test is passed. Table 16 shows that the regression effect is significant and the regression coefficient is positive. It shows that users' trust in personalized business has a significant positive impact on attitude in the absence of other factors. The value of the Adjusted $\mathrm{R}^{2}$ is 0.462 , showing that the explanatory power of trust to attitude is $46.2 \%$. From this, we can see that Hypothesis 9 is validated.

Table 16. Regression analysis on Trust and attitude.

\begin{tabular}{cccc}
\hline \multirow{2}{*}{ Variable } & \multicolumn{3}{c}{ Standardized Coefficient } \\
\cline { 2 - 4 } & $\beta$ & Significance \\
\hline Trust & 0.682 & $<0.001$ \\
$F$ & & 164.128 & \\
$\mathrm{R}^{2}$ & & 0.465 & \\
Adjusted $\mathrm{R}^{2}$ & & 0.462 & \\
$N$ & & 191 & \\
\hline
\end{tabular}

Trust is users' psychological dependence on enterprises, and the attitude of participation is also users' psychological tendency. Thus, it is understandable that trust has a positive impact on attitude. In other words, when users trust a company a lot, they are much likely to have a positive attitude to accept personalized businesses offered by the company.

\subsection{Mediating Effects Analysis}

In this section, we use the hierarchical regression method to verify the mediating effect of attitude between different factors. We first present the mediating effect analysis of perceived usefulness and behavior intention in Section 5.4.1. Then, we discuss the mediating effect analysis of perceived ease of use and behavior intention in Section 5.4.2. Section 5.4.3 presents the mediating effect analysis of trust and behavior intention. Section 5.4.4 discusses the mediating effect of perceived usefulness on perceived ease of use and attitude. Finally, in Section 5.4.5, we present the mediating effect of perceived usefulness on perceived ease of use and behavior intention.

In the following subsections, we first perform the regression analysis of the direct variables on the mediating variable, and then perform the regression analysis of the direct variables on the target variable. Finally, we select the direct variables and the mediating variable as the independent variables to conduct the regression analysis on the target variable. If the target variable is weakened by the direct variables, we can conclude that the mediating effect exists.

\subsubsection{Attitude on Perceived Usefulness and Behavior Intention}

In this study, we take perceived usefulness as the independent variable and behavior intention as the dependent variable. Then, we conduct regression analysis on perceived usefulness and behavior 
intention. The results are shown in Table 17. As shown in the table, the Adjusted $R^{2}$ is 0.276 , meaning that the explanatory power of perceived usefulness to behavior intention is $27.6 \%$. This is also validated by the $F$ test and the $T$ test.

Table 17. Regression analysis on perceived usefulness and behavior intention.

\begin{tabular}{ccccccccc}
\hline $\begin{array}{c}\text { Independent } \\
\text { Variable }\end{array}$ & $\mathbf{R}^{2}$ & $\begin{array}{c}\text { Adjusted } \\
\mathbf{R}^{2}\end{array}$ & $\boldsymbol{F}$ & Sig. & $\begin{array}{c}\text { Standardized } \\
\text { Coefficient } \boldsymbol{\beta}\end{array}$ & $\boldsymbol{T}$ & Sig & VIF \\
\hline $\mathrm{PU}$ & 0.280 & 0.276 & 73.387 & $<0.001$ & 0.529 & 8.567 & $<0.001$ & 1 \\
\hline
\end{tabular}

Next, we take perceived usefulness and attitude as the independent variables and behavior intention as the dependent variable. The results of the regression analysis on perceived usefulness, attitude, and behavior intention are shown in Table 18. Here, the Adjusted $R^{2}$ is 0.481 , which is validated by the $F$ test and the $T$ test. Based on Tables 17 and 18, we can see that the Adjusted $\mathrm{R}^{2}$ in Table 18 increases by $20.5 \%$ compared with that in Table 17 . In addition, the standardized regression coefficient $\beta$ of perceived usefulness is changed from 0.529 in Table 16 to 0.185 in Table 18. Although both values of $\beta$ in the two tables are statistically significant at the 0.001 level, the fact of $0.185<0.529$ indicates that the effect of perceived usefulness on behavior intention decreases. The value of VIF for perceived usefulness and attitude is less than 10, meaning that there is no serious collinearity. As a result, attitude plays a partial mediating role between perceived usefulness and behavior intention; thus Hypothesis 6 is established.

Table 18. Regression analysis on perceived usefulness, attitude, and behavior intention.

\begin{tabular}{ccccccccc}
\hline $\begin{array}{c}\text { Independent } \\
\text { Variable }\end{array}$ & $\mathbf{R}^{\mathbf{2}}$ & $\begin{array}{c}\text { Adjusted } \\
\mathbf{R}^{\mathbf{2}}\end{array}$ & $\boldsymbol{F}$ & Sig. & $\begin{array}{c}\text { Standardized } \\
\text { Coefficient } \boldsymbol{\beta}\end{array}$ & $\boldsymbol{T}$ & Sig & VIF \\
\hline PU & 0.486 & 0.481 & 88.913 & $<0.001$ & 0.185 & 2.816 & $<0.001$ & 1.574 \\
Attitude & & & & & 0.570 & 8.690 & 0.005 & 1.574 \\
\hline
\end{tabular}

According to the results, we can see that users first have a stage of attitude before they participate in personalized businesses. That is, perceived usefulness first stimulates users' attitude towards personalized businesses. A positive attitude will lead to high willingness to participate in personalized businesses. The results of analysis also show that perceived usefulness can directly affect users' willingness to participate in personalized businesses.

\subsubsection{Attitude on Perceived Ease of Use and Behavior Intention}

The regression analysis on perceived ease of use and behavior intention is carried out by setting perceived ease of use as the independent variable and behavior intention as the dependent variable. The results are shown in Table 19. In this regression analysis, the Adjusted $R^{2}$ is 0.168 , indicating that the explanatory power of perceived ease of use to behavior intention is $16.8 \%$, which is validated by the $F$ test and the $T$ test.

Table 19. Regression analysis on perceived ease of use and behavior intention.

\begin{tabular}{ccccccccc}
\hline $\begin{array}{c}\text { Independent } \\
\text { Variable }\end{array}$ & $\mathbf{R}^{\mathbf{2}}$ & $\begin{array}{c}\text { Adjusted } \\
\mathbf{R}^{\mathbf{2}}\end{array}$ & $\boldsymbol{F}$ & Sig. & $\begin{array}{c}\text { Standardized } \\
\text { Coefficient } \boldsymbol{\beta}\end{array}$ & $\boldsymbol{T}$ & Sig & VIF \\
\hline PEOU & 0.172 & 0.168 & 39.325 & $<0.001$ & 0.415 & 6.271 & $<0.001$ & 1 \\
\hline
\end{tabular}

Next, we use perceived ease of use and attitude as independent variables. Behavior intention is used as the dependent variable. The results of the regression analysis of perceived ease of use, attitude and behavior intention are shown in Table 20. The Adjusted $R^{2}$ is 0.482 , which is validated by the 
$F$ test and the $T$ test. In Tables 18 and 20, we can see that the Adjusted $R^{2}$ in Table 20 increases by $31.4 \%$ compared with that in Table 19. In addition, the standardized regression coefficient $\beta$ of perceived ease of use is changed from 0.415 in Table 19 to 0.165 in Table 20. As $0.165<0.415$, we can see that the effect of perceived ease of use on behavior intention is weakened. Further, the value of VIF for perceived ease of use and attitude is less than 10, showing that there is no serious collinearity. As a result, attitude plays a partial mediating role between perceived ease of use and behavior intention, which shows that Hypothesis 5 is established.

Table 20. Regression analysis on attitude, perceived ease of use, and behavior intention.

\begin{tabular}{ccccccccc}
\hline $\begin{array}{c}\text { Independent } \\
\text { Variable }\end{array}$ & $\mathbf{R}^{2}$ & $\begin{array}{c}\text { Adjusted } \\
\mathbf{R}^{\mathbf{2}}\end{array}$ & $\boldsymbol{F}$ & Sig. & $\begin{array}{c}\text { Standardized } \\
\text { Coefficient } \boldsymbol{\beta}\end{array}$ & $\boldsymbol{T}$ & Sig & VIF \\
\hline PEOU & 0.487 & 0.482 & 88.274 & $<0.001$ & 0.165 & 2.884 & 0.004 & 1.199 \\
Attitude & & & & & 0.614 & 10.743 & $<0.001$ & 1.199 \\
\hline
\end{tabular}

The above results show that users need to take a stage of behavior attitude before they take the actual behavior. Perceived ease of use first motivates users' attitude towards personalized businesses, and a positive acceptance attitude can make users increase their behavior intention. Attitude plays a partly intermediary role, indicating that perceived ease of use can directly affect users' behavior intention. When personalized businesses are easy to understand and to use, it will lower the cost of users to participate in personalized businesses and does not require users to evaluate the quality of customized products or services. To this end, the mediating effect of users' participation attitude is weakened.

\subsubsection{Attitude on Trust and Behavior Intention}

The regression analysis on the mediating effects of attitude on trust and behavior information is carried out by setting behavior information as the dependent variable and trust as the independent variable. The results are shown in Table 21. In this regression analysis, the Adjusted $R^{2}$ is 0.397 . This means that trust's interpretation power on $\mathrm{BI}$ is $39.7 \%$, which is validated by the $F$ test and the $T$ test.

Table 21. Regression analysis on behavior information and trust.

\begin{tabular}{ccccccccc}
\hline $\begin{array}{c}\text { Independent } \\
\text { Variable }\end{array}$ & $\mathbf{R}^{\mathbf{2}}$ & $\begin{array}{c}\text { Adjusted } \\
\mathbf{R}^{\mathbf{2}}\end{array}$ & $\boldsymbol{F}$ & Sig. & $\begin{array}{c}\text { Standardized } \\
\text { Coefficient } \boldsymbol{\beta}\end{array}$ & $\boldsymbol{T}$ & Sig & VIF \\
\hline trust & 0.397 & 0.394 & 124.293 & $<0.001$ & 0.630 & 11.149 & $<0.001$ & 1 \\
\hline
\end{tabular}

Next, we use trust and attitude as the independent variables and conduct regression analysis on trust, attitude, and behavior information. The results are shown in Table 22. The Adjusted $\mathrm{R}^{2}$ is 0.515 , which is validated by the $F$ test and the $T$ test. From Tables 21 and 22, we can see that the Adjusted $\mathrm{R}^{2}$ in Table 22 increases by $11.6 \%$ compared with that in Table 21. Meanwhile, the standardized regression coefficient $\beta$ of trust is changed from 0.630 in Table 21 to 0.309 in Table 22. Both values of $\beta$ are statistically significant at the 0.001 level, but, as $0.309<0.630$, we can infer that the effect of trust on behavior intention decreases. The value of VIF for trust and attitude is also less than 10, showing that there is no serious collinearity. As a result, attitude plays a partial mediating role between trust and behavior intention, indicating that Hypothesis 10 is established. 
Table 22. Regression analysis on behavior information, trust, and attitude.

\begin{tabular}{ccccccccc}
\hline $\begin{array}{c}\text { Independent } \\
\text { Variable }\end{array}$ & $\mathbf{R}^{\mathbf{2}}$ & $\begin{array}{c}\text { Adjusted } \\
\mathbf{R}^{\mathbf{2}}\end{array}$ & $\boldsymbol{F}$ & Sig. & $\begin{array}{c}\text { Standardized } \\
\text { Coefficient } \boldsymbol{\beta}\end{array}$ & $\boldsymbol{T}$ & Sig & VIF \\
\hline $\begin{array}{c}\text { trust } \\
\text { attitude }\end{array}$ & 0.515 & 0.510 & 99.994 & $<0.001$ & 0.309 & 4.450 & $<0.001$ & 1.868 \\
\hline
\end{tabular}

Due to psychological similarity, users' trust in personalized businesses is closely connected with users' subjective attitude. Therefore, trust is very likely to affect users' behavior intention through user attitude. The analyzing results show that attitude plays a partial mediating role. A possible reason is that firms or brands trusted by users can reduce user perceived risks for personalized businesses, which can also urge users participate in personalized businesses.

\subsubsection{Perceived Usefulness on Perceived Ease of Use and Attitude}

First, we perform the regression analysis on perceived ease of use and attitude by setting attitude as the dependent variable and perceived ease of use as the independent variable. The analysis results are shown in Table 23. The Adjusted $R^{2}$ is 0.166 , that is, the perceived ease of use interpretation of attitude is $11.6 \%$, which is validated by the $F$ test and the $T$ test.

Table 23. Regression analysis on perceived ease of use and attitude.

\begin{tabular}{ccccccccc}
\hline $\begin{array}{c}\text { Independent } \\
\text { Variable }\end{array}$ & $\mathbf{R}^{\mathbf{2}}$ & $\begin{array}{c}\text { Adjusted } \\
\mathbf{R}^{2}\end{array}$ & $\boldsymbol{F}$ & Sig. & $\begin{array}{c}\text { Standardized } \\
\text { Coefficient } \boldsymbol{\beta}\end{array}$ & $\boldsymbol{T}$ & Sig & VIF \\
\hline PEOU & 0.166 & 0.161 & 37.546 & $<0.001$ & 0.407 & 6.128 & $<0.001$ & 1 \\
\hline
\end{tabular}

Next, we set perceived usefulness and perceived ease of use as independent variables to measure their mediating effects on attitude. The results of regression analysis are shown in Table 24. The Adjusted $\mathrm{R}^{2}$ is 0.397 , which is validated by the $F$ test and the $T$ test. In Tables 23 and 24, we can see that the Adjusted $\mathrm{R}^{2}$ in Table 24 increased by $23.1 \%$ compared with the Adjusted $\mathrm{R}^{2}$ in Table 23. Meanwhile, the standardized regression coefficient $\beta$ of perceived ease of use is changed from 0.407 in Table 23 to 0.197 in Table 24 . Both values of the standardized regression coefficient $\beta$ are statistically significant at the 0.001 level. However, the fact $0.197<0.407$ indicates that the effect of perceived ease of use on attitude has been weakened. The VIF value for perceived ease of use and Perceived usefulness is less than 10, meaning that there is no serious collinearity. As a result, perceived usefulness plays a partial mediating role between perceived ease of use and attitude, assuming that Hypothesis 7 is established.

Table 24. Regression analysis on perceived usefulness, perceived ease of use, and attitude.

\begin{tabular}{ccccccccc}
\hline $\begin{array}{l}\text { Independent } \\
\text { Variable }\end{array}$ & $\mathbf{R}^{\mathbf{2}}$ & $\begin{array}{c}\text { Adjusted } \\
\mathbf{R}^{\mathbf{2}}\end{array}$ & $\boldsymbol{F}$ & Sig. & $\begin{array}{c}\text { Standardized } \\
\text { Coefficient } \boldsymbol{\beta}\end{array}$ & $\boldsymbol{T}$ & Sig & VIF \\
\hline $\begin{array}{c}\text { PEOU } \\
\text { PU }\end{array}$ & 0.397 & 0.391 & 61.920 & $<0.001$ & 0.197 & 3.184 & 0.002 & 1.191 \\
& & & & & 0.525 & 8.495 & $<0.001$ & 1.191 \\
\hline
\end{tabular}

The results show that perceived usefulness is partly mediated by perceived ease of use and attitude. When personalized businesses are relatively easy for users to use, users can be stimulated to participate in personalized businesses, leading to a positive attitude towards personalized businesses. However, if personalized businesses of an enterprise do not bring expected benefits to users, users may not have high behavior intention even if personalized businesses are easy to use. 


\subsubsection{Perceived Usefulness on Perceived Ease of Use and Behavior Intention}

First, we perform the regression analysis on perceived ease of use and behavior information by setting behavior information as the dependent variable and perceived ease of use as the independent variable. The analysis results are shown in Table 25. The Adjusted $R^{2}$ is 0.168 , showing that the perceived ease of use interpretation of behavior information is $16.8 \%$, which is validated by the $F$ test and the $T$ test.

Table 25. Regression analysis on perceived ease of use and attitude.

\begin{tabular}{ccccccccc}
\hline $\begin{array}{c}\text { Independent } \\
\text { Variable }\end{array}$ & $\mathbf{R}^{\mathbf{2}}$ & $\begin{array}{c}\text { Adjusted } \\
\mathbf{R}^{\mathbf{2}}\end{array}$ & $\boldsymbol{F}$ & Sig. & $\begin{array}{c}\text { Standardized } \\
\text { Coefficient } \boldsymbol{\beta}\end{array}$ & $\boldsymbol{T}$ & Sig & VIF \\
\hline PEOU & 0.172 & 0.168 & 39.325 & $<0.001$ & 0.415 & 6.271 & $<0.001$ & 1 \\
\hline
\end{tabular}

Next, we set perceived usefulness and perceived ease of use as the independent variables to measure their mediating effects on behavior intention. The results of regression analysis are shown in Table 26. The Adjusted $\mathrm{R}^{2}$ is 0.322 , which is validated by the $F$ test and $T$ test. From Tables 25 and 26 we can see that the Adjusted $R^{2}$ in Table 26 increases by $15.4 \%$ compared with that in Table 25. Meanwhile, the standardized regression coefficient $\beta$ of perceived ease of use is changed from 0.415 in Table 25 to 0.242 in Table 26. Both values of the standardized regression coefficient $\beta$ are statistically significant at the 0.001 level. However, the fact of $0.242<0.415$ indicates that the effect of perceived ease of use on behavior intention has been weakened. The VIF value for perceived usefulness and perceived ease of use is less than 10, meaning that there is no serious collinearity. As a result, perceived usefulness plays a partial mediating role between perceived ease of use and attitude, assuming that Hypothesis 7 is established.

Table 26. Regression analysis on perceived usefulness, perceived ease of use, and attitude.

\begin{tabular}{ccccccccc}
\hline $\begin{array}{c}\text { Independent } \\
\text { Variable }\end{array}$ & $\mathbf{R}^{\mathbf{2}}$ & $\begin{array}{c}\text { Adjusted } \\
\mathbf{R}^{\mathbf{2}}\end{array}$ & $\mathbf{F}$ & Sig. & $\begin{array}{c}\text { Standardized } \\
\text { Coefficient } \boldsymbol{\beta}\end{array}$ & $\mathbf{T}$ & Sig & VIF \\
\hline PEOU & 0.329 & 0.322 & 46.057 & $<0.001$ & 0.242 & 3.711 & $<0.001$ & 1.191 \\
PU & & & & & 0.432 & 6.623 & $<0.001$ & 1.191 \\
\hline
\end{tabular}

Perceived usefulness plays a partial mediating role between perceived ease of use and behavior intention. This result has two implications. First, perceived ease of use can reduce the cost of users to participate in personalized businesses, which can lead to high behavior intention. Second, even if personalized businesses are easy to use, it will not always satisfy user needs unless personalized businesses are demonstrated to be useful for users.

\subsection{Control-Variable Analysis}

User participation in personalized business may be related to some user attributes such as gender and educational background. Thus, in this section we conduct a comparative study to measure the influence of user attributes on behavior intention.

The control variables in this study include gender and educational background. We use the SPSS software (SPSS Inc., Chicago, IL, USA) to test the interferential effects of these control variables in different types of sample data. The results of non-standardized coefficient are shown in Table 27. We can see that only gender has a significant moderating effect on perceived usefulness and behavior intention, while others are not influential. Compared with the female group, the perceived usefulness of the male group has a higher impact on behavior intention. The fact $0.672>0.398$ shows that male users pay more attention to the usefulness of personalized businesses, while females are greatly influenced by psychological trust and perceived ease of use, which will reduce the importance of perceived usefulness. 
Table 27. Analysis results of control variables including gender and education background.

\begin{tabular}{|c|c|c|c|c|c|}
\hline \multirow{2}{*}{$\begin{array}{l}\text { Control } \\
\text { Variable }\end{array}$} & \multirow{2}{*}{ Relationship } & \multirow{2}{*}{ Group } & \multicolumn{2}{|c|}{ Standardized Coefficient } & \multirow{2}{*}{$\mathbf{Z}$} \\
\hline & & & $\beta$ & Number of People & \\
\hline \multirow{8}{*}{ Gender } & \multirow{2}{*}{$\mathrm{PU} \rightarrow \mathrm{BI}$} & male & 0.672 & 77 & \multirow[b]{2}{*}{2.619} \\
\hline & & female & 0.398 & 114 & \\
\hline & \multirow{2}{*}{ Attitude $\rightarrow$ BI } & male & 0.701 & 77 & \multirow{2}{*}{1.142} \\
\hline & & female & 0.663 & 114 & \\
\hline & \multirow{2}{*}{$\mathrm{PEOU} \rightarrow \mathrm{BI}$} & male & 0.309 & 77 & \multirow{2}{*}{-0.085} \\
\hline & & female & 0.495 & 114 & \\
\hline & \multirow{2}{*}{ Trust $\rightarrow$ BI } & male & 0.675 & 77 & \multirow{2}{*}{0.958} \\
\hline & & female & 0.589 & 114 & \\
\hline \multirow{8}{*}{$\begin{array}{l}\text { Education } \\
\text { Background }\end{array}$} & \multirow{2}{*}{$\mathrm{PU} \rightarrow \mathrm{BI}$} & bachelor degree and below & 0.576 & 116 & \multirow{2}{*}{1.72} \\
\hline & & master and above & 0.377 & 75 & \\
\hline & \multirow{2}{*}{ Attitude $\rightarrow$ BI } & bachelor degree and below & 0.641 & 116 & \multirow{2}{*}{0.348} \\
\hline & & master and above & 0.609 & 75 & \\
\hline & \multirow{2}{*}{$\mathrm{PEOU} \rightarrow \mathrm{BI}$} & bachelor degree and below & 0.446 & 116 & \multirow{2}{*}{0.651} \\
\hline & & master and above & 0.364 & 75 & \\
\hline & \multirow{2}{*}{ Trust $\rightarrow$ BI } & bachelor degree and below & 0.700 & 116 & \multirow{2}{*}{0.879} \\
\hline & & master and above & 0.626 & 75 & \\
\hline
\end{tabular}

\subsection{Summary of Hypothesis Validation}

By combing the results described in Sections 5.1-5.4, we present the summary of the hypothesis validation in Table 28.

Table 28. Summary of hypothesis validation.

\begin{tabular}{clc}
\hline Number & \multicolumn{1}{c}{ Hypothesis } & Validation Result \\
\hline H1 & Perceived ease of use positively affects perceived usefulness & established \\
\hline H2 & Perceived ease of use positively influences attitudes & established \\
\hline H3 & Perceived usefulness positively influences attitude & established \\
\hline H4 & Attitudes positively influence behavior intention & established \\
\hline H5 & $\begin{array}{l}\text { Attitude plays an intermediary role between perceived ease } \\
\text { of use and behavior intention }\end{array}$ & partial intermediary \\
\hline H7 & $\begin{array}{l}\text { Perceived usefulness plays a mediating role between } \\
\text { perceived ease of use and attitude }\end{array}$ & partial intermediary \\
\hline H8 & $\begin{array}{l}\text { Perceived usefulness plays an intermediary role between } \\
\text { perceived ease of use and behavior intention }\end{array}$ & partial intermediary \\
\hline H9 & Trust positively influences attitude & established \\
\hline H10 & $\begin{array}{l}\text { Attitude plays an intermediary role between trust and } \\
\text { behavior intention }\end{array}$ & partial intermediary \\
\hline
\end{tabular}

The validation result column in Table 28 shows the final validation results of each hypothesis, from which we can see that $\mathrm{H} 1-\mathrm{H} 4$ and $\mathrm{H} 9$ are well established. These hypotheses correspond to research questions Q1-Q3, as presented in Table 1. This implies that the independent variables of the research model we propose in Section 3.1 are influential to user acceptance of personalized business modes. Among all the factors, perceived usefulness and perceived ease of use are two ones reflecting the advantages of personalized businesses. It is understandable that a useful and easy-to-use personalized business mode can attract users' interests and finally lead to users' participation behavior 
in personalized businesses. The factor of trust depends on both the properties of personalized businesses and specific user attributes, but we can see that trust has a positive impact on behavior intention. In other words, if users trust a specific company, they are very likely to participate in the personalized business modes provided by the company.

Regarding Hypotheses 5-8 and 10, which aim to answer research question Q4, we can see that all selected factors have partial intermediary effect on user acceptance of personalized business modes. Partial intermediary effect means that the mediating factor does have effect on the target factor, but the final behavior of user acceptance of personalized business modes are also influenced by other factors. Thus, enterprises should pay more attention to the positive effect of mediating factors and build a framework to make all factors work for the advancement of personalized businesses.

\section{Discussion}

\subsection{Research Implications}

(1) The study of this paper is based on the background of personalized business modes in the digital age, where electronic commerce and online shopping has become a part of people's daily life. Due to the variety of users, it is necessary to exploit personalized business modes. This paper aims to answer several research questions by modeling and quantifying user acceptance of personalized business modes based on questionnaire data. We propose a research model based on the integration of the TAM model, trust, and attitude. This model augments the application of the widely used TAM model and offers referential values for other related research. In addition, we present empirical results on user acceptance of participating in personalized businesses. These results can provide new research insights for advancing personalized business modes, e.g., designing operational schemes for personalized businesses.

(2) This paper studies users' behavior intention in personalized business modes, and is valuable for enterprises to realize the importance of developing personalized business modes. Enterprises need to pay more attention to personalized business modes. With the rapid development of economics and social businesses, users' business demands have changed a lot. More and more people want to personalize their business modes so that they can get better experiences in business and learning activities. User acceptance of personalized business modes reflects the broad market prospects for customization. Thus, enterprises need to keep reforming their development models to meet user needs.

(3) We introduce trust as a new factor influencing personalized businesses. Trust is an important indicator of consumer behavior in the Internet environment, and we incorporate trust into the research model to model user acceptance of personalized business modes. The empirical research in this paper shows that trust will affect users' attitude and behavior intention on personalized business modes. Therefore, a sound trust mechanism is needed for advancing personal business modes. To attract more users to participate in personalized businesses, one key issue is to eliminate users' concerns about personalized business modes. On the one hand, companies can strive to improve their brand images, thereby enhancing users' brand loyalty. On the other hand, enterprises should abide by the commitment to users, to ensure that users participate in customized businesses in a timely manner to obtain convenient services.

(4) We find that attitude plays an intermediary role among perceived usefulness, perceived ease of use, trust and behavior intention. Perceived usefulness and perceived ease of use can affect users' behavior intention by using attitude as the mediating factor. Further, they can directly affect users' behavior intention. Therefore, enterprises should pay more attention to perceived ease of use and perceived usefulness when starting personalized businesses. On the one hand, users' profit in personalized business modes should be enhanced. It is necessary in personalized businesses to let users get tangible benefits from personalized businesses. Users may expect personalized business modes to facilitate their own consumption, and to improve their quality of consumption as well. There are also some other aspects that may bring extra benefits to users exploiting personalized businesses. 
However, enterprises have to carefully design the specific schemes and systems to better assist users to carry out personalized businesses. On the other hand, enterprises need to improve their services and reduce the difficulty of public participation. In the empirical study, consumers' perceived ease of use of personalized businesses has a significant impact on users' attitude and behavior intention to participate in personalized businesses. Thus, it is better for enterprises to establish a good channel for communication and feedbacks in the process of personalized businesses. Through such a channel, users can communicate with service providers and express their comments on business modes. Enterprises can also provide support for users to self-define customization details, such as user interface, modules, and processes, to offer better experiences for users when carrying out personalized businesses.

(5) The data used in this paper mainly come from a survey on young people. Young people live, learn and entertain in the digitalized environment since their childhood. Their familiarity and dependence on the Internet are significantly higher than other old people. Our study shows that the demand of young consumers for products is no longer satisfied with traditional business modes, which calls for personalized business modes. The characteristics of young consumers also make this study practicable and applicable, e.g., on electricity consumption for youth groups.

(6) The study in this paper finds that attitude has a central role on user acceptance of personalized business modes. Thus, it is very important for enterprises to consider users' attitude when advancing personalized businesses. Enterprises should not only improve their personalized services or products, but also focus on the brand image of personalized businesses in the market. Our study has shown that users' trust on brands will lead to a positive attitude towards personalized business modes, which will in turn lead to participation behavior in personalized businesses.

\subsection{Suggestions}

Based on the empirical analysis in this study, we further make the following suggestions for enterprises to better develop personal business modes:

(1) Enterprises need to pay more attention to personalized business modes.

With the rapid development of economics and social businesses, users' business demands have changed a lot. More and more people want to personalize their business modes so that they can get better experiences in business and learning activities. User acceptance of personalized business modes reflects the broad market prospects for customization. Thus, enterprises need to keep reforming their development models to meet user needs.

(2) A sound trust mechanism is needed for advancing personal business modes.

The empirical research in this paper shows that trust will affect users' attitude and behavior intention on personalized business modes. To attract more users to participate in personalized businesses, one key issue is to eliminate users' concerns about personalized business modes. On the one hand, companies can strive to improve their brand images, thereby enhancing users' brand loyalty. On the other hand, enterprises should abide by the commitment to users, to ensure that users participate in customized businesses in a timely manner to obtain convenient services.

(3) Users' profit in personalized business modes should be enhanced.

It is necessary in personalized businesses to let users get tangible benefits from personalized businesses. Users may expect personalized business modes to facilitate their own consumption, and to improve their quality of consumption as well. Some other aspects might bring extra benefits to users exploiting personalized businesses. However, enterprises have to carefully design the specific schemes and systems to better assist users to carry out personalized businesses. 
(4) Enterprises need to improve their services and reduce the difficulty of public participation.

In the empirical study, consumers' perceived ease of use of personalized businesses has a significant impact on users' attitude and willingness to participate in personalized businesses. Thus, it is better for enterprises to establish a good channel for communication and feedbacks in the process of personalized businesses. Through such a channel, users can communicate with service providers and express their comments on business modes. Enterprises can also provide supports for users to self-define customization details, such as user interface, modules, and processes, to offer better experiences for users when carrying out personalized businesses.

\section{Conclusions}

In this paper, we analyze the major factors that influence user acceptance of personalized business modes. In particular, we propose a research model based on the TAM (Technology Acceptance Model) model to study user acceptance of personalized business modes via some tailor-made independent variables, including perceived usefulness, perceived ease of use, and trust. We also introduce a mediating factor, i.e., attitude, to reflect the influence of independent variables on the dependent variable named behavior intention. Based on the research model, we use the structural-equation method to conduct an empirical analysis on questionnaire data from the Internet. We present comprehensive results from various aspects including reliability and validity, factor analysis, correlation analysis, regression analysis, mediating effects analysis and control-variable analysis. The results show that perceived usefulness, trust, and perceived ease of use have significant influence on user acceptance of personalized business modes, and perceived ease of use impacts perceived usefulness. In addition, gender plays an adjusting role between perceived usefulness and perceived ease of use.

Acknowledgments: We would like to thank the editors and anonymous reviewers for their suggestions and comments to improve the quality of the paper. This paper is partially supported by the National Science Foundation of China (No. 71273010 and No. 61672479) and the Doctor Start-up Fund of Anhui University. We also thank Jianfei Wang for his advice on the revision of this paper.

Author Contributions: Jie Zhao designed this study and drafted the paper in English; Suping Fang conceived and designed the experiments; and Peiquan Jin revised the paper critically for important intellectual contents.

Conflicts of Interest: The authors declare no conflict of interest.

\section{References}

1. China Internet Network Information Center (CNNIC). The Thirty-Ninth China Statistical Report on the Development of the Internet. Available online: https://www.cnnic.net.cn/hlwfzyj/hlwxzbg/201601/ P020160122469130059846.pdf (accessed on 19 October 2017).

2. Choi, J.; Lee, D. The influence of purchasing context and reversibility of choice on consumer responses toward personalized products and standardized products. Proc. Psychol. Rep. 2016, 118, 510-526. [CrossRef] [PubMed]

3. Liu, S.; Liu, F. Network sales and customization system design of ceramic products. Comput. Integr. Manuf. Syst. 2002, 8, 1548-1550.

4. Davis, F. Perceived usefulness, perceived ease of use and user acceptance of information technology. MIS Q. 1989, 13, 319-340. [CrossRef]

5. Meyer, A.; Ferdows, K. Integration of information systems in manufacturing. Int. J. Oper. Prod. Manag. 1985, 5, 5-12. [CrossRef]

6. Helander, M.; Jiao, J. Research on E-product development (ePD) for mass customization. Technovation 2002, 22, 717-724. [CrossRef]

7. Walsh, J.; Roche, D.; Foping, F. NitroScript: A PHP template engine for customizing of E-commerce applications. In Proceedings of the 2012 International Conference for Internet Technology and Secured Transactions, London, UK, 10-12 December 2012. 
8. Asenov, D.; Müller, P. Customizing the visualization and interaction for embedded domain-specific languages in a structured editor. In Proceedings of the 2013 IEEE Symposium on Visual Languages and Human Centric Computing, San Jose, CA, USA, 15-19 September 2013.

9. Satyen, U.; Love, W. How to customize digital avionics but spend less. In Proceedings of the 16th DASC AIAA/IEEE Conference on Digital Avionics System, Irvine, CA, USA, 30 October 1997.

10. Fogliatto, F.; Silveira, G.; Borenstein, D. The mass customization decade: An updated review of the literature. Int. J. Prod. Econ. 2012, 138, 14-25. [CrossRef]

11. Wang, Y.; Ma, H. Industry 4.0: A way from mass customization to mass personalization production. Adv. Manuf. 2017, 5, 311-320. [CrossRef]

12. Yang, D.; Miao, R.; Wu, H.; Zhou, Y. Product configuration knowledge modeling using ontology web language. Expert Syst. Appl. 2009, 36, 4399-4411. [CrossRef]

13. Yang, D.; Dong, M. A constraint satisfaction approach to resolving product configuration conflicts. Adv. Eng. Inf. 2012, 26, 592-602. [CrossRef]

14. Wu, D.; Zhang, G.; Lu, J.A. Fuzzy preference tree-based recommender system for personalized business-to-business E-services. IEEE Trans. Fuzzy Syst. 2015, 23, 29-43. [CrossRef]

15. Kim, H.; Lee, Y.; Yim, H.; Cho, N. Design and implementation of a personalized business activity monitoring system. In Proceedings of the International Conference on Human-Computer Interaction, Beijing, China, 22-27 July 2007.

16. Jiao, J.; Helander, M. Development of an electronic configure-to-order platform for customized product development. Comput. Ind. 2006, 57, 231-244. [CrossRef]

17. Yang, Y.; Zhang, X.; Liu, F.; Xie, Q. An internet-based product customization system for CIM. Robot. Comput. Integr. Manuf. 2005, 21, 109-118. [CrossRef]

18. Grosso, C.; Forza, C.; Trentin, A. Supporting the social dimension of shopping for personalized products through online sales configurators. J. Intell. Inf. Syst. 2017, 49, 9-35. [CrossRef]

19. Zheng, P.; Yua, S. User-experience based product development for mass personalization: A case study. Procedia CIRP 2017, 63, 2-7. [CrossRef]

20. Tseng, M.; Jiao, J.; Merchant, M. Design for mass customization. CIRP Ann. Manuf. Technol. 1996, 45, $153-156$. [CrossRef]

21. Lv, H.; Wan, Y.; Wu, F. Effect of online personalization services on complementary firms. Electron. Commer. Res. Appl. 2017, 24, 12-22. [CrossRef]

22. Lai, P. The literature review of technology adoption models and theories for the novelty technology. J. Inf. Syst. Technol. Manag. 2017, 14, 21-38.

23. Tarhini, A.; Arachchilage, N.; Masa'deh, R.; Abbasi, M. A critical review of theories and models of technology adoption and acceptance in information system research. Int. J. Technol. Diffus. 2015, 6, 58-77. [CrossRef]

24. Mehrabian, A.; Russell, J. The basic emotional impact of environments. Percept. Motor. Skills 1974, 38, $283-301$. [CrossRef] [PubMed]

25. Fishbein, M.; Ajzen, I. Belief, Attitude, Intention, and Behavior: An Introduction to Theory and Research; Reading, M.A., Ed.; Addison-Wesley: Boston, MA, USA, 1975.

26. Shih, H. An empirical study on predicting user acceptance of e-shopping on the Web. Inf. Manag. 2004, 41, 351-368. [CrossRef]

27. Ha, S.; Stoel, L. Consumer e-shopping acceptance: Antecedents in a technology acceptance model. J. Bus. Res. 2009, 62, 565-571. [CrossRef]

28. Lu, H.; Su, P. Factors affecting purchase intention on mobile shopping web site. Int. Res. 2009, 19, 442-458. [CrossRef]

29. Gefen, D.; Karahanna, E.; Straub, D. Inexperience and experience with online stores: The importance of TAM and trust. IEEE Trans. Eng. Manag. 2003, 50, 307-321. [CrossRef]

30. Vijayasarathy, L. Predicting consumer intentions to use online shopping: The case for an augmented technology acceptance model. Inf. Manag. 2004, 41, 747-762. [CrossRef]

31. Ko, E.; Kim, E.; Lee, E. Modeling consumer adoption of mobile shopping for fashion products in Korea. Psychol. Mark. 2009, 26, 669-687. [CrossRef]

32. Xie, K.; Lee, Y. Social media and brand purchase: Quantifying the effects of exposures to earned and owned social media activities in a two-stage decision making model. J. Manag. Inf. Syst. 2015, 32, 204-238. [CrossRef] 
33. Marakarkandy, B.; Yajnik, N.; Dasgupta, C. Enabling internet banking adoption: An empirical examination with an augmented technology acceptance model (TAM). J. Enterp. Inf. Manag. 2017, 30, 263-294. [CrossRef]

34. Wallace, L.; Sheetz, S. The adoption of software measures: A technology acceptance model (TAM) perspective. Inf. Manag. 2014, 51, 249-259. [CrossRef]

35. Yu, J.; Ha, I.; Choi, M.; Rho, J. Extending the TAM for a T-commerce. Inf. Manag. 2005, 42, 965-976. [CrossRef]

36. Gefen, D.; Karahanna, E.; Straub, D. Trust and TAM in online shopping: An integrated model. MIS Q. 2003, 27, 51-90. [CrossRef]

37. Heijden, H. Factors influencing the usage of websites: The case of a generic portal in The Netherlands. Inf. Manag. 2003, 40, 541-549. [CrossRef]

38. Hars, A.; Ou, S. Working for free? Motivations of participating in open source projects. Int. J. Electron. Commer. 2002, 6, 25-39.

39. Ciffolilli, A. Phantom authority, self-selective recruitment and retention of members in virtual communities: The case of Wikipedia. First Monday 2003, 8, 57-72. [CrossRef]

40. Venkatesh, V.; Thong, J.; Xu, X. Consumer acceptance and use of information technology: Extending the unified theory of acceptance and use of technology. MIS Q. 2012, 36, 157-178.

41. Koo, D. An investigation on consumer's internet shopping behavior explained by the technology acceptance model. Asia Pac. J. Inf. Syst. 2003, 13, 141-170.

42. Chang, K.; Yang, W.; Park, Y. An analysis on trust factors of B2C electronic commerce. Inf. Policy 2002, 9, 3-17. [CrossRef]

43. Che, H.; Yang, C. Examining wechat users' motivations, trust, attitudes, and positive world-of-mouth: Evidence from China. Comput. Hum. Behav. 2014, 41, 104-111.

(C) 2018 by the authors. Licensee MDPI, Basel, Switzerland. This article is an open access article distributed under the terms and conditions of the Creative Commons Attribution (CC BY) license (http:// creativecommons.org/licenses/by/4.0/). 